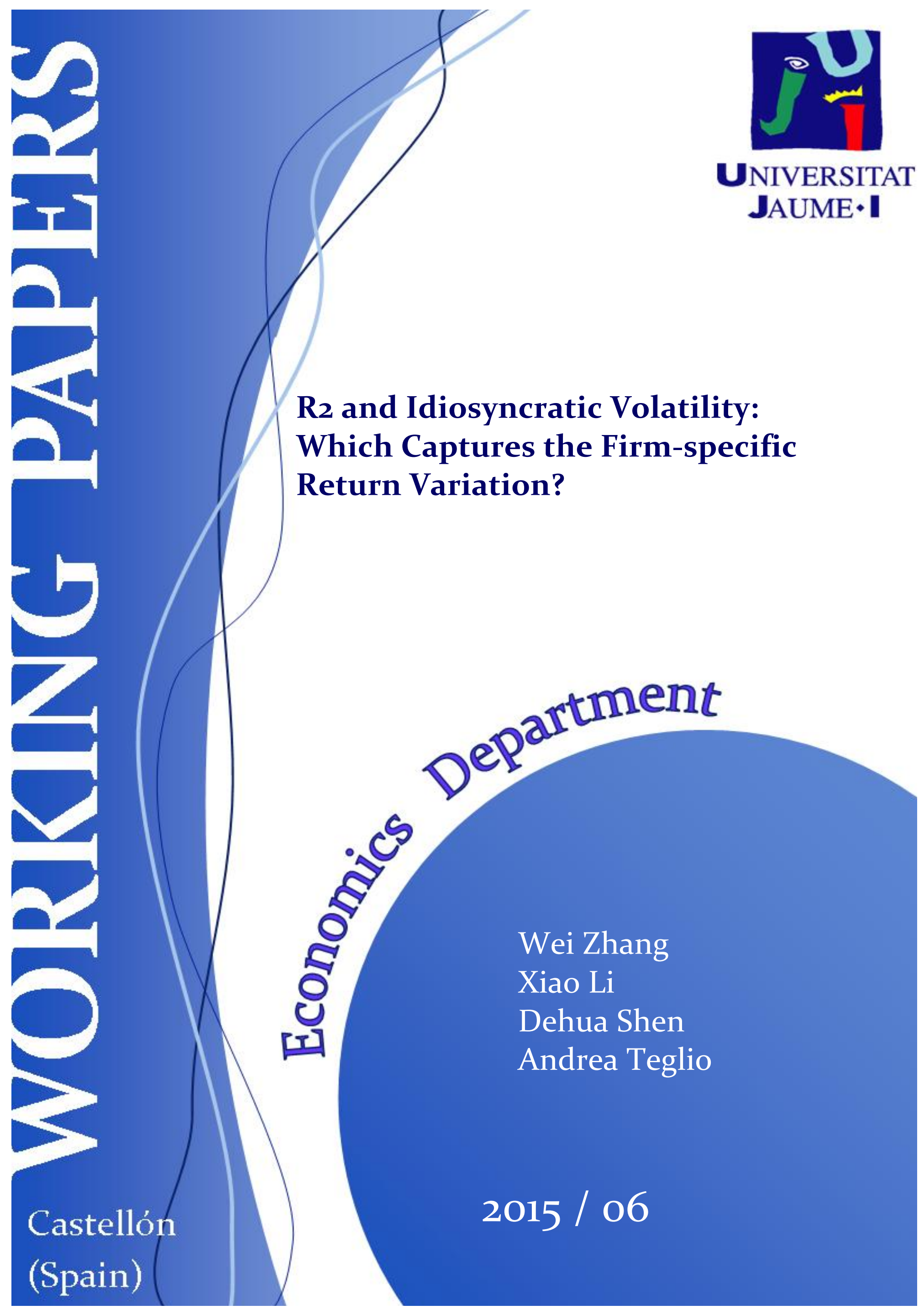




\title{
R2 and Idiosyncratic Volatility: Which Captures the Firm-specific Return Variation?
}

\author{
Wei Zhang \\ College of Management and Economics \\ China Center for Social Computing \& Analytics \\ Tianjin University \\ weiz@tju.edu.cn
}

\section{Dehua Shen}

Universitat Jaume I

Department of Economics

shen@uji.es

\author{
Xiao Li \\ College of Management and Economics \\ China Center for Social Computing \& Analytics \\ Tianjin University \\ little_two@126.com
}

Andrea Teglio

Universitat Jaume I

Department of Economics

teglio@uji.es

\section{5 / 06}

\begin{abstract}
A growing literature regards $\mathrm{R} 2$ and idiosyncratic volatility as the proxies for firm-specific return variation and examines their role in several aspects of firm's information environment. However, the question on choosing the appropriate proxy, i.e., R2 or idiosyncratic volatility, has been completely ignored. In this paper, given the unique short selling mechanism in China, we examine the changes in R2 and idiosyncratic volatility around the demarcation of information environment, respectively. The empirical findings suggest that both R2 and idiosyncratic volatility are satisfying proxies for firm-specific return variation when the information environment for individual firm is deteriorated. The R2 may not be a suitable proxy when the information environment for individual firm is improved. In that sense, we caution scholars to consider the development of capital market and the speed of information diffusion when adopting our results.
\end{abstract}

Keywords: R2; Idiosyncratic volatility; Short selling; Firm-specific return variation; Quasi-natural experiment; Information environment

JEL classification: G14, G15 


\title{
$\mathbf{R}^{2}$ and Idiosyncratic Volatility: Which Captures the Firm-specific Return Variation?
}

\author{
Wei Zhang ${ }^{1,2}, \mathrm{Xiao} \mathrm{Li}^{1,2}$, Dehua Shen ${ }^{3,{ }^{*}}$ and Andrea Teglio ${ }^{3}$ \\ 1. College of Management and Economics, Tianjin University, Tianjin, China; \\ 2. China Center for Social Computing and Analytics, Tianjin University, Tianjin, China \\ 3. Department of Economics, Universitat Jaume I, Castellón, Spain
}

\begin{abstract}
:
A growing literature regards $\mathrm{R}^{2}$ and idiosyncratic volatility as the proxies for firm-specific return variation and examines their role in several aspects of firm's information environment. However, the question on choosing the appropriate proxy, i.e., $\mathrm{R}^{2}$ or idiosyncratic volatility, has been completely ignored. In this paper, given the unique short selling mechanism in China, we examine the changes in $\mathrm{R}^{2}$ and idiosyncratic volatility around the demarcation of information environment, respectively. The empirical findings suggest that both $\mathrm{R}^{2}$ and idiosyncratic volatility are satisfying proxies for firm-specific return variation when the information environment for individual firm is deteriorated. The $\mathrm{R}^{2}$ may not be a suitable proxy when the information environment for individual firm is improved. In that sense, we caution scholars to consider the development of capital market and the speed of information diffusion when adopting our results.
\end{abstract}

Keywords: $\mathrm{R}^{2}$; Idiosyncratic volatility; Short selling; Firm-specific return variation; Quasi-natural experiment; Information environment

JEL classification: G14, G15

Acknowledgments: We are grateful for the NSFC (71320107003 and 71271144).

\footnotetext{
* Corresponding author: Dehua Shen

Tel.: +86 13820038920; E-mail address: shen@uji.es
} 


\section{Introduction}

According to the traditional asset pricing model, the total risk of underlying assets is the sum of idiosyncratic risk (the variance of the residual from a regression of individual stock return on the market return) and the systematic risk (the synchronous movement of individual stock return with the market return, often denoted as $\mathrm{R}^{2}$ ). To measure the firm-specific return variation, both the $\mathrm{R}^{2}$ and the idiosyncratic volatility are two prominent proxies, which are supposed to be equivalent by most scholars. Roll (1988) argues that $\mathrm{R}^{2}$ represents the non-diversifiable factors explaining the actual price movement of individual stock return. Morck, Yeung and Yu (2000) argue that $\mathrm{R}^{2}$ is related to investors' arbitraging ability on firm-specific information. In that sense, $\mathrm{R}^{2}$ is lower among developed economy stock market compared with emerging markets. Durnev, Morck, Yeung and Zarowin (2003) define the idiosyncratic volatility as firm-specific return variation and conclude that greater idiosyncratic volatility is associated with more informative stock prices. Also, Durnev, Morck and Yeung (2004) follow Roll (1988) in distinguishing the firm-specific return variation from the systematic variation and empirically find that firm-specific return variation is due to informed trading. Hutton, Marcus and Tehranian (2009) view $\mathrm{R}^{2}$ as firm-specific information and find that more opaque environment for firms' financial reports is associated with higher $\mathrm{R}^{2}$. Taken together, all these studies treat higher idiosyncratic risk as equivalent to lower $\mathrm{R}^{2}$ and vice versa.

On the contrary, a recent paper by Li, Rajgopal and Venkatachalam (2014) provide an alternative opinion that $\mathrm{R}^{2}$ and idiosyncratic volatility are not interchangeable. Based on the regression of the CAPM model, they show that the relationship between $\mathrm{R}^{2}$ and earnings quality may be quite different from that between idiosyncratic volatility and earnings quality. They argue that whether $\mathrm{R}^{2}$ or idiosyncratic volatility is a more appropriate proxy is in large attribute to the type of information (noise or value-relevant information) firm-specific return variation captures. However, their conclusion is solely drawn in view of the relationship 
between firm-specific return variation and the earnings quality, which is only one specific covariate of interest. Other variables of interest, e.g., financial reporting quality, audit quality, disclosure quality and sophistication of investors, may yield distinct results from earnings quality (Harris, 2003; Rajgopal and Venkatachalam, 2011). Focusing on the changes in idiosyncratic volatility is insufficient to give a conclusive remark on the interchangeable or not-interchangeable relationship between $\mathrm{R}^{2}$ and idiosyncratic volatility. In other words, it is necessary to figure out the suitability of $\mathrm{R}^{2}$ and idiosyncratic volatility as proxies for firm-specific return variation under different information environments.

In this paper, we investigate this issue by utilizing a quasi-natural experiment derived from the unique short selling mechanism in Chinese stock market. On 31 March 2010, the China Securities Regulatory Commission (CSRC) removed the restrictions on short selling for some selected stocks, which gave rise to a list of stocks. This designated list has revised several times in the following years, including adding and deleting stocks. For adding the stocks into the designated list, this lift of short selling restrictions can be regarded as a sign of the improving of information environment for individual firm (Diamond and Verrechia, 1987); while deleting the stocks from the designated list implies that the information environment become deteriorated (Boulton and Braga-Alves, 2010). This unique mechanism naturally provide us a rarely opportunity to examines the impact of information environment on the suitability of $\mathrm{R}^{2}$ and idiosyncratic volatility as proxies for firm-specific return variation, which characterizes our study in three aspects. Firstly, other than previous literature (Hutton, Marcus and Tehranian, 2009; Rajgopal and Venkatachalam, 2011; Li, Rajgopal and Venkatachalam, 2014) primarily relied on the magnitude of the specific covariate of interest, e.g., analyst coverage, accounting accruals, and earnings, as the proxies for information environment changes, this demarcation of information environment is obviously more clear and direct. Secondly, with both cross-sectional and time-series analysis, to some extent, it rules out other confounding factors affecting the changes in $\mathrm{R}^{2}$ and idiosyncratic volatility, e.g. sophistication of investors. Thirdly, the setting of this unique mechanism also enables us to identify the sources of 
changes in $\mathrm{R}^{2}$ and idiosyncratic volatility and thus obtain a panoramic observation.

\section{Econometric model}

In accord with Cai and Xia (2014), we further view $\mathrm{R}^{2}$ and idiosyncratic volatility from a pure econometric perspective and express them as the following equation:

$$
R^{2}=\frac{\beta^{2} V_{M}}{\beta^{2} V_{M}+I V}
$$

Where, $R^{2}$ is the synchronous movement of individual stock return with the market return, $\beta$ is the co-movement coefficient with the market, $V_{M}$ is the market return variation and $I V$ is the idiosyncratic volatility.

Based on equation (1), we construct the $R^{2}, \beta$, market return variation $\left(V_{M}\right)$ and idiosyncratic volatility $(I V)$. For stock i, we regress the standard market model for the pre and the post event windows separately:

$$
r_{i t k}=\alpha_{i k}+\beta_{i k} r_{m t k}+\varepsilon_{i t k}
$$

Where $r_{i t k}$ is the daily stock return of event $i$ on day $t$ in window $k, r_{m t k}$ is the CSI 300 stock index return on day $\mathrm{t}$ in window $\mathrm{k}, \varepsilon_{\mathrm{itk}}$ is the regression error term. The adjusted $\mathrm{R}^{2}$ of equation 2 is the $\mathrm{R}^{2}$ term we use in this paper. The sample variance of $r_{m t k}$ is the market volatility in equation 1 . The idiosyncratic volatility is expressed as:

$$
I V_{i k}=\frac{i}{T-1} \sum_{t=1}^{T-1} \varepsilon_{i t k}^{2}
$$

Where $\mathrm{T}$ is the totally number of trading days in stock event $\mathrm{i}$.

\section{The data and empirical results}

Our sample period covers the period from 30 March 2009 to 30 January 2014. A stock-event is said to be an "addition event" if it is added to the designation list and a "deletion event" if it is deleted from the designation list. Totally, there are 542 addition events and 59 deletion events from the Shanghai Stock Exchange and Shenzhen Stock Exchange that have at least 120 trading days' records before and after each event. Table 1 presents the list changes, addition events and deletion events. We use the (-120 trading days, -1 trading days) and the (1 trading days, 120 trading days) 
as the pre-event window and post-event window, respectively. Due to some strict restrictions (market value, number of shareholder, price change ratio and daily average turnover) of the addition event, it's impossible for us to find an appropriate control group ${ }^{1}$. Besides, the focus on this paper is on the suitability of $\mathrm{R}^{2}$ and idiosyncratic volatility as proxies for firm-specific return variation, rather than examining the impact of short selling mechanism on the market quality. The capital data are from the Wind financial database.

Table 1: list changes, addition events and deletion events

\begin{tabular}{cccc}
\hline Effective date & Number of stocks on the list & Addition events & Deletion events \\
\hline $2010 / 3 / 31$ & 90 & 90 & N/A \\
$2010 / 7 / 1$ & 90 & 5 & 5 \\
$2010 / 7 / 29$ & 90 & 1 & 1 \\
$2011 / 12 / 5$ & 278 & 189 & 1 \\
$2013 / 1 / 31$ & 500 & 276 & 54 \\
$2013 / 3 / 6$ & 499 & N/A & 1 \\
$2013 / 3 / 7$ & 498 & N/A & 1 \\
$2013 / 3 / 29$ & 496 & N/A & 2 \\
$2013 / 5 / 2$ & 495 & N/A & 1 \\
$2013 / 5 / 3$ & 494 & N/A & 1 \\
\hline Cumulated & 494 & 561 & 67 \\
\hline
\end{tabular}

Table 2 illustrates the pairwise changes in $\mathrm{R}^{2}, \beta$, idiosyncratic volatility and market volatility of addition events. The $\mathrm{R}^{2}$ does not change around the addition events. Neither the mean nor the median changes at an acceptable level ( $p$-value $>0.05$ ). The mean (median) $\beta$ decreases from 1.0987 (1.1129) to 1.0713 (1.0781), which is significant at $1 \%$ level. The changes of market volatility is statistically significant at $1 \%$ level ( $\mathrm{p}$-value $=0.000$ ). The mean idiosyncratic volatility does not change around the addition events, but the median idiosyncratic volatility experience statistically significant changes at $1 \%$ level (z-value $=2.7417$, p-value $=0.0061)$. These empirical findings suggest that, to some extent, the idiosyncratic volatility is a better proxy for firm-specific return variation when the information environment for individual firm is improved.

\footnotetext{
${ }^{1}$ For the selection criteria of the eligible stocks, see: http://www.shlca.cn/2012-04-11/140279028_2.html.
} 
Table $2: \mathrm{R}^{2}, \beta$, market volatility and idiosyncratic volatility of addition event

\begin{tabular}{|c|c|c|c|c|c|}
\hline & pre & post & post-pre & t-value/z-value & p-value \\
\hline \multicolumn{6}{|l|}{$\mathrm{R}^{2}$} \\
\hline Mean & 0.4225 & 0.4345 & 0.0120 & 1.8573 & 0.0638 \\
\hline median & 0.4345 & 0.4416 & 0.0071 & 1.9321 & 0.0533 \\
\hline \multicolumn{6}{|l|}{$\beta$} \\
\hline Mean & 1.0987 & 1.0713 & -0.0274 & 2.4598 & 0.0142 \\
\hline median & 1.1129 & 1.0781 & -0.0348 & 2.3655 & 0.0180 \\
\hline \multicolumn{6}{|l|}{ Market volatility } \\
\hline Mean & 0.0002 & 0.0002 & 0.0000 & 20.0123 & 0.0000 \\
\hline median & 0.0002 & 0.0003 & 0.0001 & 13.6032 & 0.0000 \\
\hline \multicolumn{6}{|c|}{ Idiosyncratic volatility } \\
\hline Mean & 0.0004 & 0.0004 & 0.0000 & 1.6559 & 0.0983 \\
\hline median & 0.0003 & 0.0003 & 0.0000 & 2.7417 & 0.0061 \\
\hline
\end{tabular}

Table 3 illustrates the pairwise changes in $\mathrm{R}^{2}, \beta$, idiosyncratic volatility and market volatility of deletion events, which shows inconsistent results with those in table 2 . The $\mathrm{R}^{2}, \beta$, market volatility and idiosyncratic volatility all change statistically at $1 \%$ significant level ( $\mathrm{p}$-value $=0.000$ ). Specifically, the mean (median) $\mathrm{R}^{2}$ decreases by $21.68 \%(20.19 \%)$, while the mean (median) idiosyncratic volatility increases by $100 \%(50 \%)$. Hence, changes in idiosyncratic volatility are greater than those in $\mathrm{R}^{2} . \mathrm{In}$ that sense, we empirically find that, both $\mathrm{R}^{2}$ and idiosyncratic volatility are satisfying proxies for firm-specific return variation when the information environment for individual firm is deteriorated. The greater changes in idiosyncratic volatility suggest that idiosyncratic volatility captures more firm-specific return variation. 
Table $3: \mathrm{R}^{2}, \beta$, market volatility and idiosyncratic volatility of deletion event

\begin{tabular}{|c|c|c|c|c|c|}
\hline & pre & post & post-pre & t-value/z-value & p-value \\
\hline \multicolumn{6}{|l|}{$\mathrm{R}^{2}$} \\
\hline Mean & 0.5262 & 0.4121 & -0.1141 & 5.1250 & 0.0000 \\
\hline median & 0.5462 & 0.4359 & -0.1103 & 4.2948 & 0.0000 \\
\hline \multicolumn{6}{|l|}{$\beta$} \\
\hline Mean & 1.0404 & 0.8781 & -0.1623 & 6.3082 & 0.0000 \\
\hline median & 1.0782 & 0.9011 & -0.1771 & 5.1704 & 0.0000 \\
\hline \multicolumn{6}{|l|}{ Market volatility } \\
\hline Mean & 0.0002 & 0.0002 & 0.0000 & 16.6553 & 0.0000 \\
\hline median & 0.0002 & 0.0003 & 0.0001 & 6.7011 & 0.0000 \\
\hline \multicolumn{6}{|c|}{ Idiosyncratic volatility } \\
\hline Mean & 0.0002 & 0.0004 & 0.0002 & 5.7348 & 0.0000 \\
\hline median & 0.0002 & 0.0003 & 0.0001 & 5.1402 & 0.0000 \\
\hline
\end{tabular}

\section{Conclusions}

What can we conclude from the above-mentioned findings? In the beginning, we review the literature on using the $\mathrm{R}^{2}$ or idiosyncratic volatility as the proxies for firm-specific return variation. These two proxies are often regarded as interchangeable. The only exception comes from Li, Rajgopal and Venkatachalam (2014), who correlate firm-specific return variation and earnings quality, find contradictory results and conclude that these two proxies are not interchangeable. In this paper, given the unique short selling mechanism in China, we further examine the changes in $\mathrm{R}^{2}$ and idiosyncratic volatility around the demarcation of information environment, respectively. The empirical findings suggest that both $\mathrm{R}^{2}$ and idiosyncratic volatility are satisfying proxies when the information environment for individual firm is deteriorated. The $\mathrm{R}^{2}$ is not a suitable proxy when the information environment for individual firm is improved. These results complement the existing literature on figuring out under what information environment we could choose a better proxy for firm-specific return variation, rather than just arguing they are not interchangeable. However, our results also remind us to be cautious in regarding idiosyncratic volatility is always better than $\mathrm{R}^{2}$. Because firm-specific return variation is also correlated to the development of the capital market (Morck, Yeung and Yu, 2000) as well as the 
diffusion speed to different types of information (Hong, Lim and Stein, 2000). We leave this for future research. 


\section{Reference:}

[1] Li, B. et al. (2014). R2 and Idiosyncratic Risk Are Not Interchangeable, The Accounting Review 89(6): 2261-2295.

[2] Roll, R. (1988). R2, Journal of Finance 43(3): 541-566.

[3] Morck, R. et al. (2000). The information content of stock markets: why do emerging markets have synchronous stock price movements? Journal of Financial Economics 58(1-2): $215-260$.

[4] Durnev, A. et al. (2004). Value-Enhancing Capital Budgeting and Firm-specific Stock Return Variation, Journal of Finance 59(1): 65-105.

[5] Hutton, A. P. et al. (2009). Opaque financial reports, R2, and crash risk, Journal of Financial Economics 94(1): 67-86.

[6] Rajgopal, S. and M. Venkatachalam (2011). Financial reporting quality and idiosyncratic return volatility, Journal of Accounting and Economics 51(1-2): 1-20.

[7] Harris, L., Trading and Exchanges: Market Microstructure for Practitioners. Oxford University Press, 2003.

[8] Boulton, T. J. and M. V. Braga-Alves (2010). The skinny on the 2008 naked short-sale restrictions, Journal of Financial Markets 13(4): 397-421.

[9] Cai, J. and L. Xia (2014). When $\mathrm{R}^{2}$ meets the short-sales constraints, Economics Letters 125(3): 336-339.

[10] Hong, H. et al. (2000). Bad news travels slowly: Size, analyst coverage, and the profitability of momentum strategies, Journal of Finance 55(1): 265-295. 